bridge in a crevasse at a depth of $28 \mathrm{~m}$. below the surface level. He had crashed through two higher snow bridges to land on one which spanned the crevasse where it was still wide open. Miraculously he was not injured. As he was in the crevasse for over two hours his eyes must have become well adapted. He stated that the open crevasse continued to a considerable depth below the snow bridge, and this was confirmed by the time taken by snowballs to fall to the bottom. This crevasse must have reached at least the maximum depth of $120 \mathrm{ft} .(36.5 \mathrm{~m}$.) mentioned by Mr. Miller.

The pronounced bulging claimed by Dr. Nye for walls exceeding $34 \mathrm{~m}$. would apply not only to crevasses but to all ice walls. Glacier fronts in Greenland have often been found to reach twice, and occasionally three times, that height above the fjord level, but no marked bulging near the water level has been observed (see, for instance, E. Sorge, Umiamako- und Rinkgletscher, Universal-GrönlandExpedition 1932). It may be objected that, due to calving, the ice walls near the front of the glacier are changing too rapidly to allow marked bulging. But there are in the Arctic, as in the Antarctic, great numbers of stranded icebergs with walls considerably higher than $30 \mathrm{~m}$. above the water, for instance on Jakobshavn Iceberg Bank. They often remain in the same position for many months, and occasionally for more than a year. I do not know of any observations which show that they bulge markedly under their own weight. These icebergs generally derive, at least in the Arctic, from low-lying glacier tongues whose surfaces melt to a depth of several metres every year. As much of this melt water infiltrates, and a considerable fraction of it transfers its heat of fusion to the ice by freezing, the temperature of most of these icebergs cannot be considerably, if at all, below freezing point (Expéditions Polaires Francaises, Serie Scientifique, No. 10, 1949 [1950], p. 30). The absence of yielding, therefore, cannot be attributed to a low temperature.

But it should be noted that according to Dr. E. Orowan (Fournal of Glaciology, Vol. I, No. 5, I 949, p. 235) the critical height of 10 to $30 \mathrm{~m}$. applies only to ice columns with a height greater than their width, and not to ice slabs with horizontal dimensions comparable with their height. Therefore only the height of seracs or the depth of crevasses in a heavily dissected area would be limited in this way; more widely spaced crevasses, such as are generally found in the névé area or the walls of compact icebergs or stagnant glaciers, could exceed $30 \mathrm{~m}$. in height even if their temperature were at freezing point.

University of Melbourne,

Dept. of Meteorology

I7 May 1954

Fritz LOEWE

\title{
COMMENTS ON DR. LOEWE'S LETTER AND NOTES ON CREVASSES
}

\author{
By Dr. J. F. Nye \\ (University of Bristol)
}

Dr. LoEwE's letter is a stimulus to improve our theories. The present theory of the depth of crevasses is so rudimentary that one should not expect more than a rough agreement with experience. Orowan and Ward put forward a simple theory ${ }^{1}$ which connected the maximum depth of crevasses, $d$, with the "yield stress" of ice. If the yield stress of ice in compression is taken to be 2 bars (approximately $\left.2 \mathrm{~kg} . / \mathrm{cm} .{ }^{2}\right), d$ is calculated as $20 \mathrm{~m}$. The calculation is successful in that it shows how plasticity theory can give a result which is in general quantitative agreement with observation. But the result cannot be regarded as anything more than a first approximation, because the calculation takes as its model not a crevasse in a flowing glacier, but a tall, slender and stationary column of ice.

The last paragraph of Dr. Loewe's letter seems to spring from a misunderstanding. If Orowan's tall, slender column model is extended so that only one horizontal dimension is infinite, the stresses and critical height do not change by more than is per cent. This follows from the well-known relation in plasticity between the yield stress in plane stress and in plane strain. Orowan's second model (which he applied to an ice cap) refers to a case where both horizontal dimensions are large; it is therefore not relevant to the crevasse problem.

The following calculation on crevasse depths gives the possibility of a more detailed comparison between theory and experiment than has been possible hitherto. Let us first assume that transverse 
crevasses can be formed wherever a longitudinal tensile stress (greater than zero) exists in a glacier. This is equivalent to saying that there will always be a sufficient number of points where the tensile strength of the ice is effectively zero. The stress analysis of a perfectly plastic glacier ${ }^{2}$ shows that, in "extending flow," a longitudinal tensile stress can exist down to a depth of approximately $d=\sigma / \rho g$, where $\sigma$ is the yield stress in extension and $\rho$ is the density of ice. Atmospheric pressure is neglected in this calculation. The longitudinal stress is $\sigma$ on the surface of the glacier; it decreases with depth and reaches zero at approximately this critical depth $d$. The question then arises, what is the value of $\sigma$ ? Previously it was guessed that $\sigma$ is about $z$ bars. Now, a better estimate of $\sigma$ could be obtained by measuring the longitudinal rate of extension, $\dot{\epsilon}$, on the glacier surface and using this in conjunction with Glen's creep formula for ice. ${ }^{3}$ Glen's formula was established for compression, but we assume that it also holds for extension. Thus we write

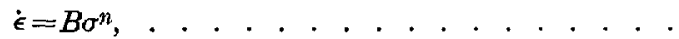

where $B$ and $n$ are constants ; and so we have, for the maximum depth of the crevasses,

$$
d=\frac{\mathrm{I}}{\rho g}\left(\frac{\dot{\epsilon}}{B}\right)^{1 / n} \text {. }
$$

Let us now consider the effect of atmospheric pressure.* It is, to a good approximation, the maximum difference of principal stresses that determines the rate of strain. Therefore, an atmospheric pressure, $p_{0}$, say, acting normally on the upper surface of the glacier, reduces by $p_{0}$ the longitudinal tensile stress needed to produce a given $\dot{\epsilon}$. The longitudinal tensile stress at the surface is thus $\left(\sigma-p_{0}\right)$, where $\sigma$ is still given by ( 1 ). The longitudinal stress now remains tensile down to a smaller depth than before, namely, $\left(\sigma-p_{0}\right) / \rho g$. (If $\sigma=2$ bars and $p_{0}=1$ bar, the thickness of the tensile layer is seen to be halved by the presence of atmospheric pressure.) A tensile crack would be expected to propagate to this depth, if, as before, we take the tensile strength of the ice to be zero. The crack will, of course, disturb the stress distribution in its neighbourhood as it propagates. If we neglect this change we have the following situation: a crack of depth $\left(\sigma-p_{0}\right) / \rho g$, with its tip in a region of zero tensile stress, and with atmospheric pressure acting within it. In these circumstances the crack will continue to propagate downwards until its tip reaches a depth where the longitudinal pressure in the ice just balances the internal pressure in the crack. This depth is $\sigma / \rho g$, and is independent of $p_{0}$. The conclusion is, that while atmospheric pressure alters the precise stresses under which the crack propagates, it does not alter the final depth that the crack reaches; for this depth is determined not by the condition of zero tensile stress but by the condition that the longitudinal stress in the glacier should be equal to atmospheric pressure. Formula (2) therefore holds independently of atmospheric pressure. Perhaps the weakest assumption made in its derivation is that the stress distribution below the level to which cracks penetrate is unaffected by the presence of the cracks. This assumption is legitimate when the crevasses are closely spaced but can easily be shown to be false when they are widely separated.

With $\rho=0.90 \mathrm{gm} . / \mathrm{cm} .^{2}, g=980 \mathrm{~cm} . / \mathrm{sec}^{2}$, and, as found by Glen for a temperature of $0^{\circ} \mathrm{C}$., $n=3.3$ and $B=0.10$ years $^{-1}$ bars $^{-n}$, we have, from (2),

where $\dot{\epsilon}$ is in years ${ }^{-1}$ and $d$ is in metres.

$$
d=22 \cdot 8 \dot{\varepsilon}^{0 \cdot 303}
$$

An experimental check of this formula would be as follows. A glacier showing transverse crevasses is selected (for example, the Mer de Glace). The surface velocity is measured at a number of points along a line perpendicular to the crevasses. The velocity measurements should extend over a sufficient time and distance for irregularities to be averaged out. Hence $\dot{\epsilon}$ is calculated. (For example, if the surface velocities of two points separated by a distance $x$ are $v_{1}$ and $v_{2}$, then $\dot{\epsilon}=\left(v_{1}-v_{2}\right) / x$.) At the same time $d$ is found by measuring the maximum depth of the crevasses.

The relation between the above calculation based on a glacier model and Orowan's calculation based on a tall column model may be seen as follows. Neglect the very small amount of shearing parallel to the bed that takes place in the upper layers of a glacier, and imagine a series of closely spaced crevasses of depth given by (2). The ice between them will tend to spread out under its own weight in the way that Orowan envisaged for an isolated column. But it must be remembered that this ice is not resting on a rigid base as in Orowan's model, but is resting on the lower layers of the glacier, which are themselves extending longitudinally at the rate $\dot{\epsilon}$. Now the vertical compressive stress

\footnotetext{
* I am indebted to Prof. F. C. Frank for a discussion on this point.
} 
$\left(\rho g d+p_{0}\right)$ producing the "Orowan spreading" of the material just above the depth $d$ exceeds the horizontal compressive stress $\left(p_{0}\right)$ by $\rho g d$. The rate of vertical compression so produced must equal the rate of longitudinal spreading (constancy of volume and plane strain), and we have seen that such a stress difference ogd produces a strain-rate $\dot{\epsilon}$. Thus, the "Orowan spreading" at the bottoms of the crevasses is exactly sufficient to ensure continuity with the longitudinal extension rate of the underlying layers of the glacier. Higher up the crevasse walls the Orowan spreading is smaller, by reason of the smaller depth, and so the ice here does not extend longitudinally as fast as the underlying ice of the glacier. This is why the crevasses open up. The argument is strictly correct for very closely spaced crevasses. For a wider spacing, further analysis is necessary.

\section{R E F E R E N C E S}

1. Discussion on "The Flow of Ice and of other Solids." fournal of Glaciology, Vol. I, I 949, No. 5, p. 235 and 238.

2. Nye, J. F. Proceedings of the Royal Society, Series A, Vol. 207,195 x, p. 554-72.

3. Glen, J. W. Fournal of Glaciology, Vol. 2, No. I 2, I952, p. I I I-I4. Nature, Vol. I72, No. 4381, I953, p. 72 I-22.

\section{COMMENTS ON CREVASSE DEPTHS}

\section{By G. Seligman}

I BELIEVE that I was originally responsible for the statement that crevasses in temperate glaciers did not in general exceed $30 \mathrm{~m}$. in depth, although Dr. Orowan, with whom I often discussed the point, no doubt based his views not on my experience but on theoretical grounds. In my paper "The structure of a temperate glacier," Geographical Fournal, Vol. 97, No. 5, 1941, p. 30r, I wrote: "I believe the great depths attributed to crevasses in the Alps are mythical. We explored many, and the greatest depth we reached was $30 \mathrm{~m}$.; a crevasse said to be at least $60 \mathrm{~m}$. deep proved to be no more than 25."

My subsequent observations in the Alps confirmed this assessment, but no doubt thęre can be exceptions, one of which Dr. Loewe has encountered.

It would be interesting to hear of actual measurements from colder regions than the Alps which could throw further light on Dr. Loewe's statement that many high ice walls in those regions must be at $0^{\circ} \mathrm{C}$.

\section{The Editor, \\ The Fournal of Glaciology}

SIR,

"Fökla mýs"

Small spheroidal, silt-packed, moss cushions, or polsters, are abundant on the terminus of Matanuska Glacier (lat. $6 \mathrm{I}^{\circ} \mathrm{N}$., long. $147^{\circ} 4 \mathrm{I}^{\prime}$ W.) in the Chugach Mountains of south central Alaska. In outward appearance, these resemble "jökla mýs" (glacier mice), described and named from observations and collections on Hrútárjökull, Iceland, by Dr. Jón Eythórsson (Fournal of Glaciology, Vol. I, No. 9, p. 503, I95 I). The jökla mýs described were moss-covered stones, whereas specimens from Matanuska Glacier are concentric moss layers in which sandy silt and a few small pebbles have been incorporated during growth.

On ro September 1950, L. L. Ray, F. C. Whitmore, Jr., A. C. Orvedal and I made a reconnaissance of the broad terminus of Matanuska Glacier. The terminus, at an altitude of approximately $1700 \mathrm{ft}$., is a gently sloping surface mantled, in places, by mounds and ridges of cobbly ablation moraine with relief as much as $50 \mathrm{ft}$. The polsters were called to my attention by Dr. Ray, who first noticed them; others of the party aided in determining their widespread occurrence.

Polsters occur on gentle slopes of bare melting ice in about the same abundance as in waters of supraglacial streams; a few were collected on patches of ablation moraine. Where they rested on exposed ice surfaces, they sometimes lay in shallow wells thawed by their insolation. There was no apparent preferred orientation of the polsters in the thaw wells.

The dominant shape is a distinctly oblate spheroid *; the shortest axis does not exceed one-half the longest, which ranges from $\mathrm{I}$ to $6 \mathrm{in}$. $(2.5$ to $15.3 \mathrm{~cm}$.). Irregular shapes are less common and of similar size. Surfaces are firmly bound with living moss, although on spheroidal types one of the two flatter sides, usually that on which it has rested most recently, has a somewhat less luxuriant

* A photograph submitted by Dr. Benninghoff showed forms practically identical with those in the photograph which illustrated Dr. Eythórsson's letter mentioned above.-Ed. 